\title{
INVESTIGATION OF LIME MORTARS AND PLASTERS FROM ARCHAEOLOGICAL EXCAVATIONS IN HIPPOS (ISRAEL) USING ELECTRON PARAMAGNETIC RESONANCE
}

\author{
ZUZANNA KABACIŃSKA ${ }^{1}$, RYSZARD KRZYMINIEWSKI ${ }^{1}$, DANUTA MICHALSKA ${ }^{2}$ \\ and BERNADETA DOBOSZ ${ }^{1}$ \\ ${ }^{1}$ Medical Physics Division, Faculty of Physics, Adam Mickiewicz University, Umultowska 85, 61-614 Poznań, Poland \\ ${ }^{2}$ Department of Dynamic and Regional Geology, Institute of Geology, Faculty of Geographical and Geological Sciences, \\ Adam Mickiewicz University, Maków Polnych 16, 61-606 Poznań, Poland
}

Received 30 June 2013

Accepted 6 December 2013

\begin{abstract}
This study presents the preliminary results of investigation of the lime mortars and plasters from archaeological excavations in Hippos (Israel), using Electron Paramagnetic Resonance (EPR) spectroscopy. The research was conducted in order to characterize the building material and its reaction to ionizing radiation. The ancient settlement Hippos, situated on the east shore of the Sea of Galilee, functioned from the $3^{\text {rd }}$ cent. BC until it was destroyed by the earthquake in 749 AD. Lime mortars and plasters show carbonate and locally gypsum character of binder and different kind of aggregate. Samples were $\gamma$-irradiated and measured using X-band EPR spectrometer. Computer Resolution Enhancement Method was applied to the complex spectra. Some of the $\gamma$-induced EPR signals were attributed to $\mathrm{CO}_{2}{ }^{-}$and $\mathrm{CO}_{3}{ }^{3-}$ paramagnetic centres. Exponential growth of the dose response curve above $1 \mathrm{kGy}$ and saturation for doses above $20 \mathrm{kGy}$ was observed. For doses lower than $1 \mathrm{kGy}$ the dose response curve has a linear character. The presence of $\gamma$-sensitive carbonate paramagnetic centres could indicate that, after further studies, well-chosen samples of mortars and plasters might be suitable for EPR dating, assuming the centres have been sufficiently bleached during the manufacturing process.
\end{abstract}

Keywords: EPR dating, lime mortars, lime plasters, calcium carbonate, resolution enhancement.

\section{INTRODUCTION}

Lime mortars and plasters are an invaluable source of information for archaeologists. Careful examination may reveal details regarding preparation techniques, types of additives and the provenance of raw material. Since mortars cannot be used again, their age reflects the time of the building's construction, whereas dating plasters can give the dates of the renovation phases.

Corresponding author: Z. Kabacińska e-mail: zuziakab@amu.edu.pl
Manufacturing of lime mortar is a result of lime heating. Calcium carbonate decomposes in high temperature forming $\mathrm{CaO}$ (burnt lime), which is then mixed with water to obtain $\mathrm{Ca}(\mathrm{OH})_{2}$ (slaked lime). The mixture of $\mathrm{Ca}(\mathrm{OH})_{2}$ with sand and other additives can be applied to the surface and then hardens by absorbing $\mathrm{CO}_{2}$ from the atmosphere. In this process slaked lime is transformed back into calcium carbonate. Manufacturing process of mortars was described for example by Hale et al. (2003), Nawrocka et al. (2005), Lindroos et al. (2007) and Heinemeier et al. (2010). 
The fact that binder absorbs $\mathrm{CO}_{2}$ during the hardening process is the basis for radiocarbon dating of mortars and plasters, described by Hale et al. (2003), Nawrocka et al. (Nawrocka et al. 2005 and 2009; Michalska Nawrocka et al., 2007); Lindroos et al. (2007) and Heinemeier et al. (2010). The radiocarbon dating of carbonate binders is possible after an appropriate preparation. It should be preceded by petrographic observations whose purpose is to examine the exact ingredients of the mortar. When the mortar aggregate consists of fragments of limestone or crushed shell that are difficult to eliminate during the preparation, the alternative is dating charcoal, if present in the sample (Goslar et al., 2009).

OSL also proved to be useful in dating lime mortars, as described by Zacharias et al. (2002) and Goedicke (2003 and 2011). This approach is based on measuring the luminescence signal of sand grains added to slaked lime during the production process. The event to be dated is the bleaching of quartz sand by sunlight during transport from the gravel pit. Bleaching ends when the grains are covered with the calcite layer. There are, however, certain limitations - some grains may not be completely bleached and as a result the obtained age can be too old.

Bleaching of the material due to heating of the lime may suggest using another dating method based on trapped electrons - Electron Paramagnetic Resonance (EPR). After the heating and formation of calcium carbonate the electron traps in mortar or plaster are empty the production of material would be therefore a zerosetting event. However, other carbonates (e.g. mollusc shells) may be added to the mortar or plaster during its production hence a careful examination of sample, including petrographic studies, might be crucial. Those assumptions would suggest that also TL could be applicable in the case of lime mortars, although to our knowledge, there have been no published studies on the possibility of dating lime mortars using TL.

EPR has been widely used in dating archaeological and geological materials such as bones, teeth, quartz, feldspar and carbonates (see e.g. Ikeya, 1993 and 2004). The principles of this method were extensively described in many works, for example by Ikeya (1993 and 2004) and Jonas (1997). EPR spectroscopy is based on the interaction of the magnetic moments of unpaired electrons in the sample with an external magnetic field, which leads to the splitting of electron energy levels. An EPR signal is observed when the quantum of electromagnetic wave energy incident on the sample is equal to the energy difference between the neighbouring energy levels. The signals' positions and mutual distances indicated by the so-called $g$-factor and hyperfine coupling constant respectively, help to attribute them to the specific paramagnetic centres. In this method the dose of radiation absorbed by the material is obtained from the dose response curve created through additional irradiation of the sample in laboratory.
This work aims at investigating lime mortars and plasters from archaeological excavations in Hippos (Israel) using EPR spectroscopy and their reaction to ionizing radiation, as the first step in evaluation of their potential for dating by this method. Since the measured samples are quite young as far as EPR is concerned, and there are no data regarding the annual doses, the actual dates were not obtained. However, those studies, together with similar investigation of lime mortars from Budinjak in Croatia (Kabacińska et al., 2012) could give important information which may be useful for future studies. The innovative aspect of this study involves also the use of Computer Resolution Enhancement Method described by Krzyminiewski (1994). This method proved to be a valuable tool in resolving the complex spectra.

\section{EXPERIMENTAL}

\section{Site and materials}

Hippos is located on the eastern shore of the Sea of Galilee (Fig. 1), near the Golan Heights. The Sea of Galilee occupies the northern part of the Jordan Rift Valley. It is a major source of fresh water in Israel.

The excavations and historical sources allowed to establish the history of Hippos. It was founded in the third century $\mathrm{BC}$, during the reign of Rome it belonged to the Decapolis cities (as mentioned by Pliny the Elder in Historia naturalis). In the Byzantine period (V-VI century) Hippos prospered as a capital of the bishopric. VIIcentury invasions of Sassanids on the Syro-Palestine and the subsequent Islamic conquest probably led to the depopulation of the city. Location of the Hippos and other settlements along the fault zone associated with the

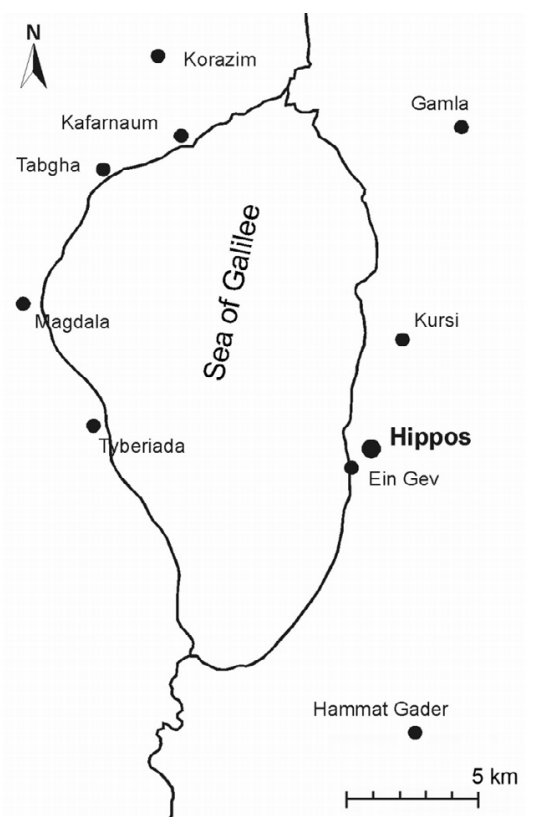

Fig. 1. The location of Hippos, eastern shore of the Sea of Galilee, Israel. 
earthquakes, significantly affected their history (Amiran et al., 1994; Marco et al., 2003). Hippos was destroyed by the earthquake in $749 \mathrm{AD}$, and has never been rebuilt.

Most of the binders samples were taken from the North-West Church (NWC) and its immediate surroundings, which were explored by a group of Polish archaeologists led by Młynarczyk and Burdajewicz. The NWC is a three-nave basilica preceded by a square stone-paved courtyard (atrium; Fig. 2). The church's walls are built of blocks of basalt and limestone. So far, the excavations have allowed to identify three chronological phases of the church. The first phase includes the construction of the church around the fifth century AD. The second phase, based on the repertoire of decorative motifs present on the mosaic floors, is dated on the late sixth century. The third phase is marked by the extension of the chancel by installing the handrails in the aisles, probably in the seventh century. The NWC was active until the earthquake of $749 \mathrm{AD}$. Adjacent to the southern wall of the church are the oil press and wine press. They are contemporary with the second, or even with the third phase of the basilica. This church was built on an earlier Roman temple (Młynarczyk, 2001; Segal et al., 2004).

Samples from Hippos were dated by radiocarbon method using AMS and GPC techniques (Michalska Nawrocka et al., 2007), which resulted in the first absolute chronology of this settlement. The results were mostly consistent with the data obtained by the archaeologists, resulting from the relative chronology. The radiocarbon dates obtained for investigated samples are shown in Table 1. The material was collected during the annual seasons of excavation, in regular consultation with archaeologists leading the works.

\section{Samples preparation}

The mortar and plaster samples were a subject of thorough petrographic observations, enabling the identification of their composition. This data led to the selection of samples for further analysis, including the ${ }^{14} \mathrm{C}$ and EPR measurements. They also allowed for a verification of the results and interpretation of the data. In addition, all samples were analysed by SEM-EDS and selected

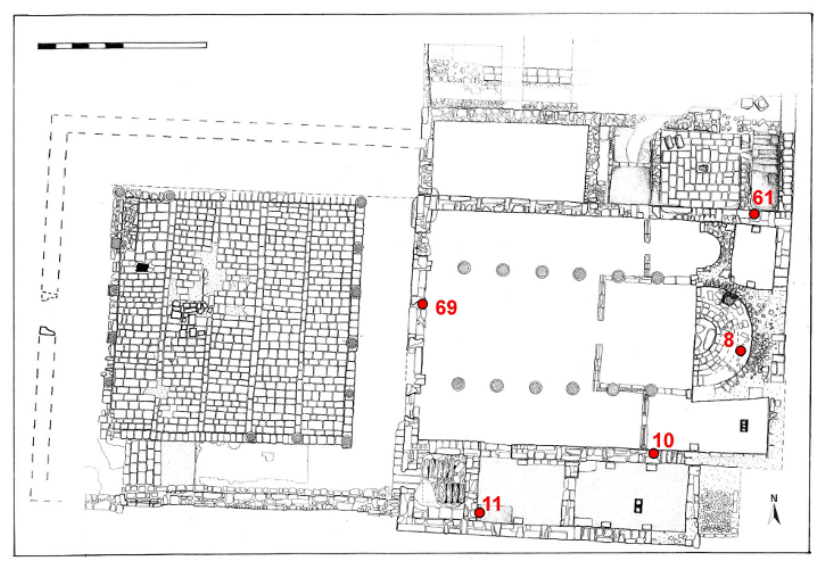

Fig. 2. The plan of the North-West Church in Hippos (drawn by Burdajewicz M., in: Segal et al., 2004) with the location of sampling points for the samples Hip8, Hip10, Hip11, Hip61 and Hip69w.

Table 1. Samples description, location and ${ }^{14} \mathrm{C}$ results for chosen samples. Radiocarbon dating made in Gliwice Radiocarbon Laboratory by GPC technique (signed as Gd) and by AMS in Poznań Radiocarbon Laboratory (signed as Poz). Result of radiocarbon dating were published by Michalska Nawrocka et al. (2007). Sample 61H used for EPR measurements is the fraction 63-80 $\mu$ m of sample Hip61.

\begin{tabular}{|c|c|c|c|c|}
\hline $\begin{array}{c}\text { Sample } \\
\text { name }\end{array}$ & Description & $\begin{array}{c}\text { Carbonate } \\
\text { content }\end{array}$ & Location & ${ }^{14} \mathrm{C}$ age \\
\hline $\mathrm{A} 1$ & $\begin{array}{l}\text { lime plaster characterized by presence of small } \\
\text { amount of basaltic-carbonatious aggregate and } \\
\text { straw traces }\end{array}$ & $78 \%$ & $\begin{array}{l}\text { North-East Church (NEC), the } \\
\text { apse }\end{array}$ & $\begin{array}{l}\text { Gd-17381 GPC (carbonate binder, } \\
\text { fraction } 45-100 \mu \mathrm{m}) \\
1140 \pm 130 \mathrm{BP} \\
\end{array}$ \\
\hline Hip8 & $\begin{array}{l}\text { lime plaster poorly compact, dusting, characterized } \\
\text { by presence of elongated pores - straws traces }\end{array}$ & $84 \%$ & $\begin{array}{l}\text { North-West Church (NWC); } \\
\text { the central apse, west wall }\end{array}$ & ( \\
\hline Hip10 & $\begin{array}{l}\text { pure lime plaster characterized by the presence of } \\
\text { large number of straw traces }\end{array}$ & $91 \%$ & $\begin{array}{l}\text { NWC, southern aisle, by the } \\
\text { balustrade, northern face }\end{array}$ & $\begin{array}{c}\text { Poz-7417 AMS (carbonate binder) } \\
1245 \pm 35 \text { BP } \\
\text { Gd-12823 GPC (carbonate binder) } \\
1310 \pm 45 \text { BP }\end{array}$ \\
\hline Hip11 & $\begin{array}{l}\text { almost pure lime plaster with single limestone frag- } \\
\text { ments and shells }\end{array}$ & $85 \%$ & $\begin{array}{l}\text { Diaconicon; south-west corner } \\
\text { of the first room }\end{array}$ & (1) \\
\hline Hip69w & $\begin{array}{l}\text { white lime mortar containing coarse-grained basal- } \\
\text { tic-carbonatious aggregate }\end{array}$ & $87 \%$ & $\begin{array}{l}\text { NWC; west wall of the main } \\
\text { nave, near the entrance; the } \\
\text { inner layer of plaster }\end{array}$ & - \\
\hline Нip61 & $\begin{array}{l}\text { mortar with admixture of basaltic-carbonatious } \\
\text { aggregate; aggregate also contains single fine } \\
\text { quartz grains, fragments of snail and bivalve shells }\end{array}$ & - & $\begin{array}{l}\text { Facade of the pastophorium, } \\
\text { northern wall }\end{array}$ & $\begin{array}{c}\text { Gd-18388 GPC (carbonate binder } \\
\text { fraction } 80-100 \mu \mathrm{m} \text { ) } \\
1080 \pm 100 \mathrm{BP} \\
\text { Poz-16078 (fraction of mortar below } \\
100 \mu \mathrm{m} \text {; separated basaltic aggre- } \\
\text { gate covered with a thin film of } \\
\text { binder) } \\
1490 \pm 30 \mathrm{BP}\end{array}$ \\
\hline
\end{tabular}


ones also by XRD at the Faculty of Geographical and Geological Sciences of Adam Mickiewicz University in Poznań. Table 1 provides a brief description of the components of each sample, the percentage of calcium carbonate and radiocarbon dates for the selected samples. All selected samples contained a carbonate binder and varied in their composition and the percentage content of the aggregate (Fig. 3). Carbonate nature of the binder was also confirmed by XRD studies. XRD patterns were attributed to $\mathrm{CaCO}_{3}, \mathrm{CaMgFeCO}_{3}$ and quartz.

Samples for EPR measurements were gently crushed and fragments of aggregate bigger than $2 \mathrm{~mm}$ of diameter were removed using a stereomicroscope. All samples were ground in a mortar. Sample $61 \mathrm{H}$ is a sieved fraction 63-80 $\mu \mathrm{m}$ of the binder Hip61. The ${ }^{14} \mathrm{C}$ dating conducted for samples from Hippos (Michalska Nawrocka et al., 2007) showed that by sieving it is possible to eliminate most of the carbonate aggregate added to lime mortar during manufacturing process. For samples of lime mortars containing both binder and aggregate of carbonatious character, the best results can be achieved for fractions below $100 \mu \mathrm{m}$. Sieving was not possible in the case of the other samples due to the lack of sufficient amount of material. All samples were ground in a mortar.

One part of each sample was analysed by EPR without additional irradiation, whereas the rest of the samples were irradiated before measurement with doses of 1,10 , 20, 50, 80 and $100 \mathrm{kGy}$ at the Institute of Applied Radia- tion Chemistry, Technical University of Łódź, using a ${ }^{60} \mathrm{Co} \gamma$-source. Additionally, sample $61 \mathrm{H}$ was irradiated with doses of 50, 100, 300, 500, 800, 2210 and $3000 \mathrm{~Gy}$, using the ${ }^{60} \mathrm{Co} \gamma$-source at the Institute of Molecular Physics, Polish Academy of Sciences in Poznań.

\section{Measurements and methods}

Measurements were performed at room temperature using X-band Bruker EPR spectrometer, EMX type, at the Medical Physics Division, Faculty of Physics, Adam Mickiewicz University in Poznań. Three different magnetic field regions were recorded for each sample: $6500 \mathrm{G}$ (full sweep width), $700 \mathrm{G}$ (the $\mathrm{Mn}^{2+}$ sextet) and $140 \mathrm{G}$ (the region around $g=2.0000$ ). Following parameters were used for the spectra: microwave power $6.315 \mathrm{~mW}$, modulation frequency $100.00 \mathrm{kHz}$, conversion time $40.960 \mathrm{~ms}$, time constant $40.960 \mathrm{~ms}$ (for sweep widths $6500 \mathrm{G}$ and $700 \mathrm{G}$ ) and $20.480 \mathrm{~ms}$ (for sweep width $140 \mathrm{G}$ ) and modulation amplitude $10.00 \mathrm{G}$ (for sweep widths $6500 \mathrm{G}$ and $700 \mathrm{G}$ ) and $1.00 \mathrm{G}$ (for sweep width $140 \mathrm{G}$ ) respectively. For EPR measurements $80 \pm 0.1 \mathrm{mg}$ of each sample was used. Uncertainty of $g$-factor obtained from spectra in $6500 \mathrm{G}$ sweep width was \pm 0.006 and \pm 0.0005 in the $140 \mathrm{G}$ range.

The Computer Resolution Enhancement Method (CREM) was applied to the spectra recorded at sweep width $140 \mathrm{G}$ in order to increase their resolution and determine the spectroscopic parameters. The CREM
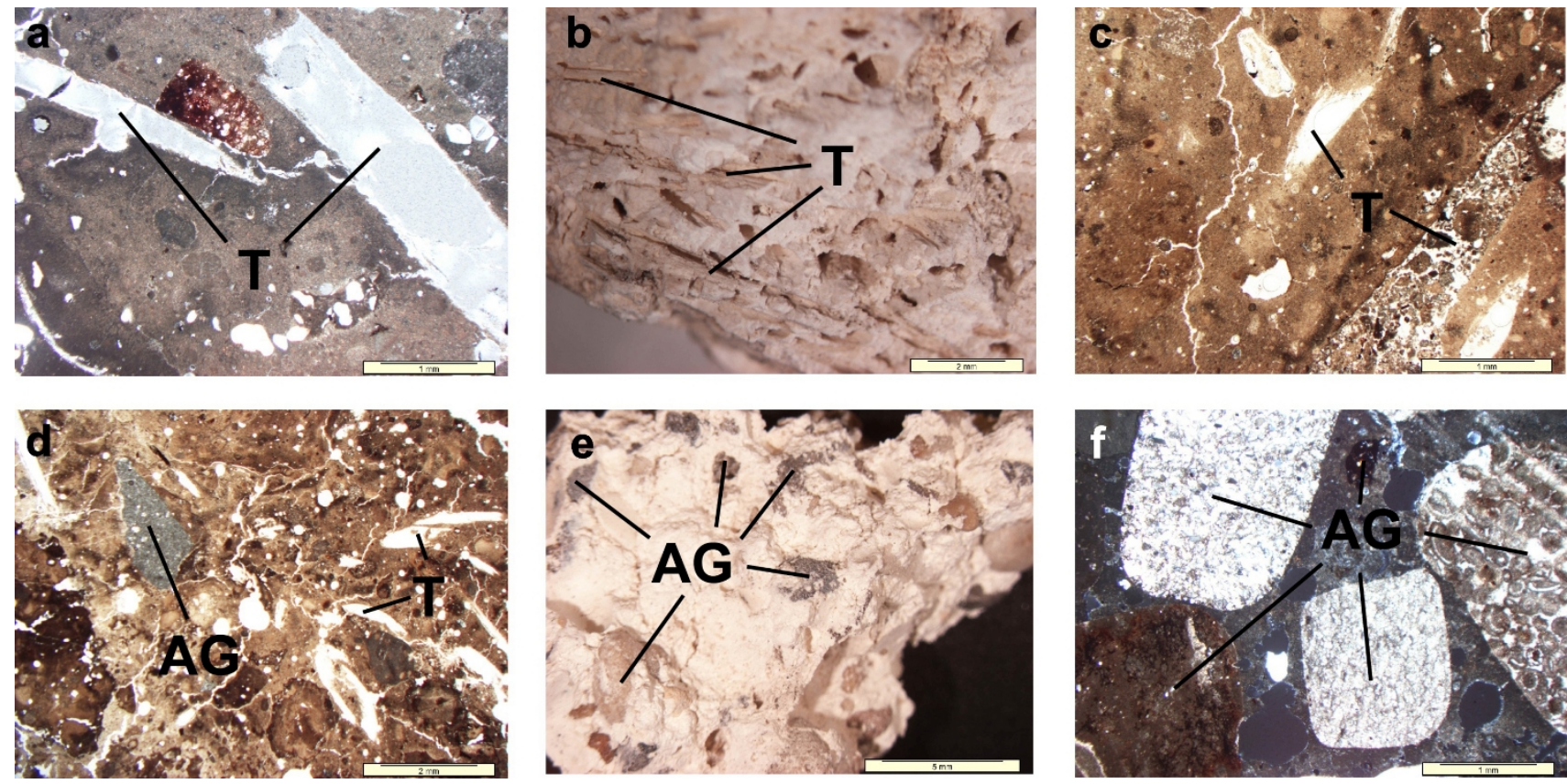

Fig. 3. Macro- and microphotographs of mortars and plasters from Hippos showing different character of the aggregate in samples; a) sample A1, lime plaster with small amount of basaltic-carbonatious aggregate and straw traces (crossed polarizers, magnification 2.5x); b, c) Hip8 and Hip10 respectively, lime plasters, only straw traces visible; d) Hip11, lime plaster with single, crushed limestone fragments and shells; e, f) Hip61, macro and respectively microphotograph of mortar with different kind of aggregate, mainly basalt and limestone fragments, shells (magnification 2.5x, crossed polarizers; polarizing light microscopy, Institute of Geology, Poznań) (partially after Michniewicz and Nawrocka, 2005). Aggregate was indicated on the figure by $A G$ and straw traces by $T$. 
procedure, based on Fourier transform, was described in detail by Krzyminiewski (1994). The shape of the spectrum can be described by the following function

$$
F(x)=\int_{-\infty}^{\infty} K\left(x-x^{\prime}\right) \psi\left(x^{\prime}\right) d x^{\prime}
$$

where the function $\psi\left(x^{\prime}\right)$ determines the positions and intensities of particular lines in the spectrum, and $K\left(x-x^{\prime}\right)$ is so-called core i.e. the function describing the shape of individual lines. The resolution of the spectrum may be enhanced by calculating $\psi(x)$ function from the equation:

$$
\psi(x)=(2 \pi)^{-\frac{1}{2}} \int_{-\infty}^{\infty} \frac{\widetilde{F}(y)}{\widetilde{K}(y)} \exp (-i y x) d y
$$

where $\widetilde{F}(y)$ is the Fourier transform of $F(x)$, and $\widetilde{K}(y)$ is the Fourier transform of $K\left(x-x^{\prime}\right)$. In the CREM procedure the core width $K\left(x-x^{\prime}\right)$ is the input parameter. The procedure of optimization was described by Krzyminiewski et al. (1998). Examples of application of this method can be found in Krzyminiewski et al. (1998), Krzyminiewski and Frąckowiak (2000) and Dobosz and Krzyminiewski (2007a, 2007b).

\section{RESULTS AND DISCUSSION}

Full-range spectra of non-irradiated samples of lime mortars an plasters form Hippos are dominated by a broad line at $g$-factor 2.029 (Fig. 4a), connected with an orthorhombic iron ion $(S=1 / 2)$. Small signal at $g=4.326$ is identified as low symmetry iron ion $\mathrm{Fe}^{3+}$ signal $(S=5 / 2)$. Sample Hip10 exhibits an additional signal at $g=3.080$ also connected with iron ions. Such signals are common in carbonates and were described for example by Ikeya (1993), Polikreti et al. (2004) and Dobosz and Krzyminiewski (2007a, 2007b). Fig. 4b shows a typical spectrum of $\mathrm{Mn}^{2+}$ hyperfine sextet, also often present in

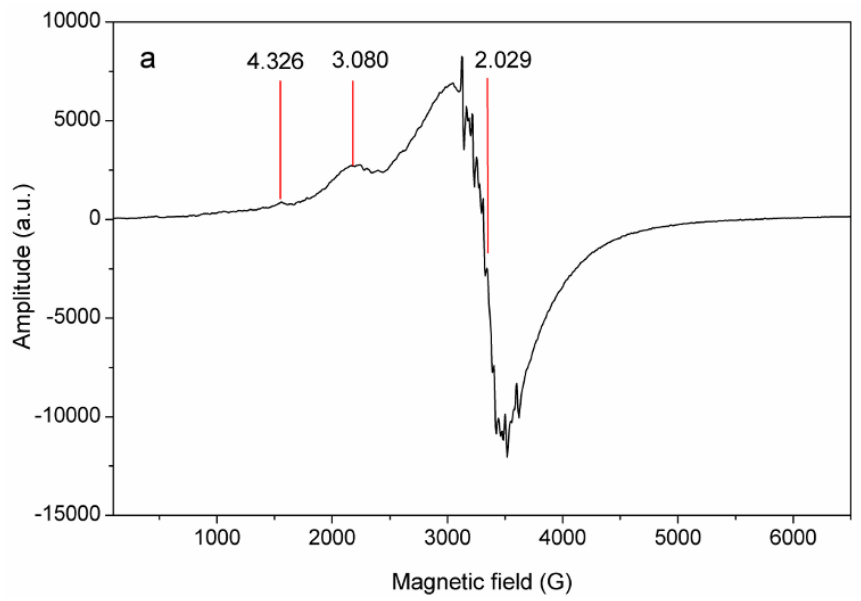

many carbonate materials. This signal is connected with $\mathrm{Mn}^{2+}$ ions substituting for $\mathrm{Ca}^{2+}$ ions in carbonate lattice, extensively described in literature (e.g. Ikeya, 1993; Jonas, 1997; Polikreti et al., 2004; Seleţchi and Duliu, 2007). Amplitudes of those initially present signals do not change with the dose of irradiation.

The signals near $g=2$, between the third and fourth main hyperfine line of $\mathrm{Mn}^{2+}$, are very weak and difficult to measure in the natural sample. After $\gamma$-irradiation intensity of the signals increased. The same signals can be observed in the spectra of all measured samples irradiated with doses of 1-100 kGy, although they differ in the intensity, as shown in Figs. 5 and 6. Spectrum of sample A1 is dominated by the triplet at $g$-factors $2.0264,2.0058$ and 1.9855, with the hyperfine coupling constant of $34.5 \mathrm{G}$. It overlaps the other signals and is present also in the spectra of the remaining samples. The $g$-factor value of 2.0057 in carbonates has been interpreted by many authors (see e.g. Barabas, 1992; Ikeya, 1993 and 2004) as the $\mathrm{SO}_{2}{ }^{-}$ centre. In this case, however, it is presumably a part of a triplet, not a single line, so its nature should be studied

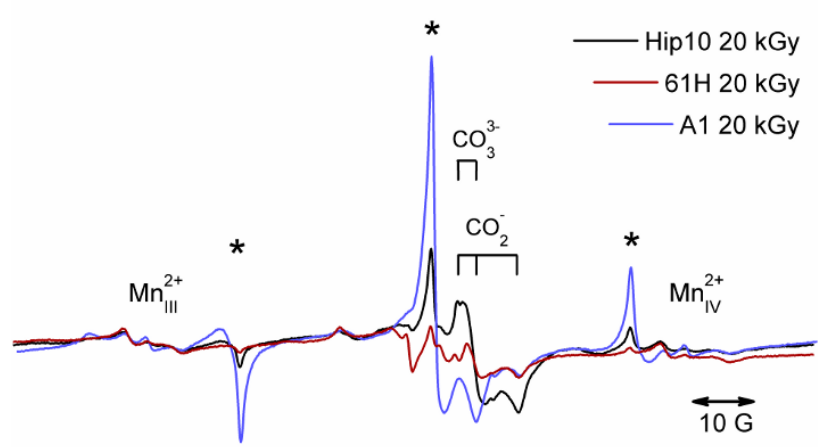

Fig. 5. EPR spectra samples $A 1, H i p 10$ and $61 \mathrm{H}$ irradiated with $20 \mathrm{kGy}$. The triplet signal is marked with *. The positions of $\mathrm{Mn}^{2+}$ (third and fourth line) and $\mathrm{CO}_{2}^{-}, \mathrm{CO}_{3}{ }^{3-}$ signals are indicated.

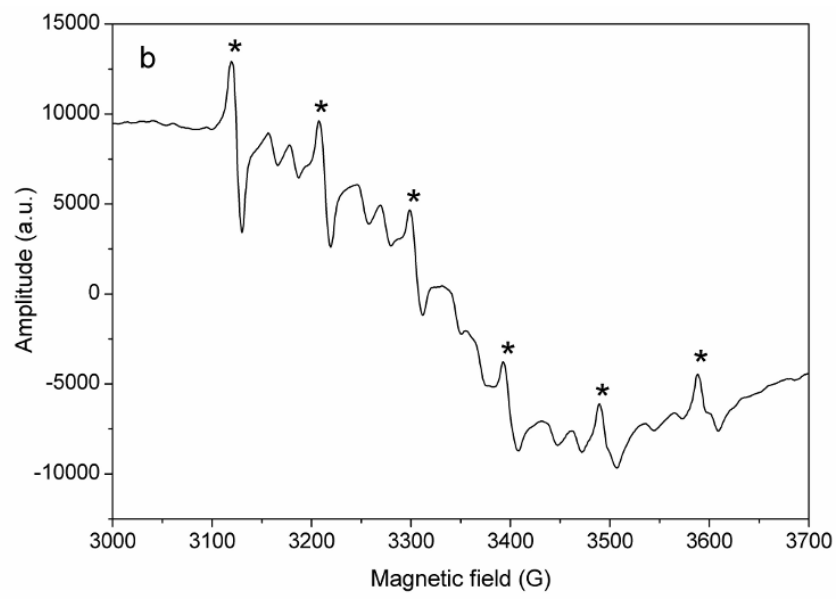

Fig. 4. EPR spectra of non-irradiated sample Hip10, sweep width $6500 \mathrm{G}$ (a) and $700 \mathrm{G}$ (b). The manganese sextet is marked with *. 
further before assigning it to this species. Sample $61 \mathrm{H}$, which is the fraction $63-80 \mu \mathrm{m}$ of a mortar, gives the EPR spectrum least affected by the presence of the triplet signal, presumably because the component that the signal was originating from was almost completely eliminated during sieving. Spectra of $61 \mathrm{H}$ exhibits the signals at $g=2.0034$, 2.0013 and 1.9971 attributed to $\mathrm{CO}_{2}{ }^{-}$species; the peaks at
2.0034 and 2.0013 may be also interpreted as the axial $\mathrm{CO}_{3}{ }^{3-}$ paramagnetic centre (Barabas, 1992; Barabas et al., 1992; Ikeya, 1993 and 2004; Callens et al., 1998; Wencka and Krzyminiewski, 2004). Other peaks can be observed at $g=2.0424,2.0209,2.0156,2.0102,2.0082,2.0057$ and 2.0048. Their identification as well as interpretation of the triplet, needs further investigation.

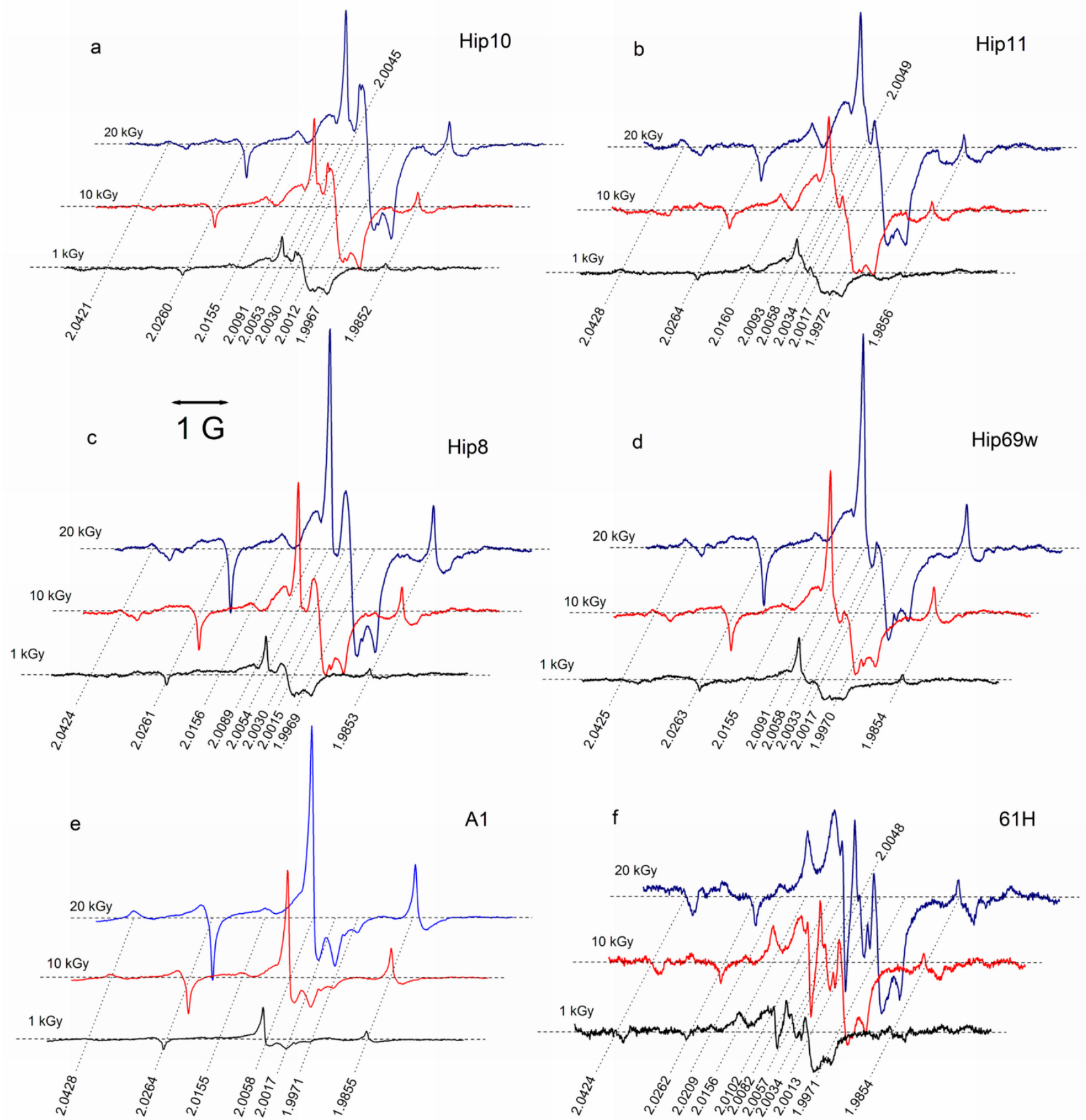

Fig. 6. EPR spectra of samples Hip10 (a), Hip11 (b), Hip8 (c), Hip69w (d), A1 (e) and 61H (f) irradiated with doses of 1, 10 and 20 kGy, after subtraction of non-irradiated sample spectrum, sweep width $140 \mathrm{G}$. 
EPR spectra of samples Hip8, Hip10, Hip11 and Hip69w share a similar structure (Fig. 6), being the combination of two spectra - sample $61 \mathrm{H}$ and $\mathrm{A} 1$ (as can be seen in Fig. 5) with different proportions. The $g$-factor values for each sample are given in Fig. 6.

The effect of lower doses of radiation on sample $61 \mathrm{H}$ (the fraction $63-80 \mu \mathrm{m}$, almost pure binder) was also investigated (Fig. 7). Irradiation with doses of 50 and 100 Gy had very little effect on the signal near $g=2$. Radiation-induced signals are pronounced, however still weak at $300 \mathrm{~Gy}$. For doses of 500 and 800 Gy the structure of the spectra is clearer.

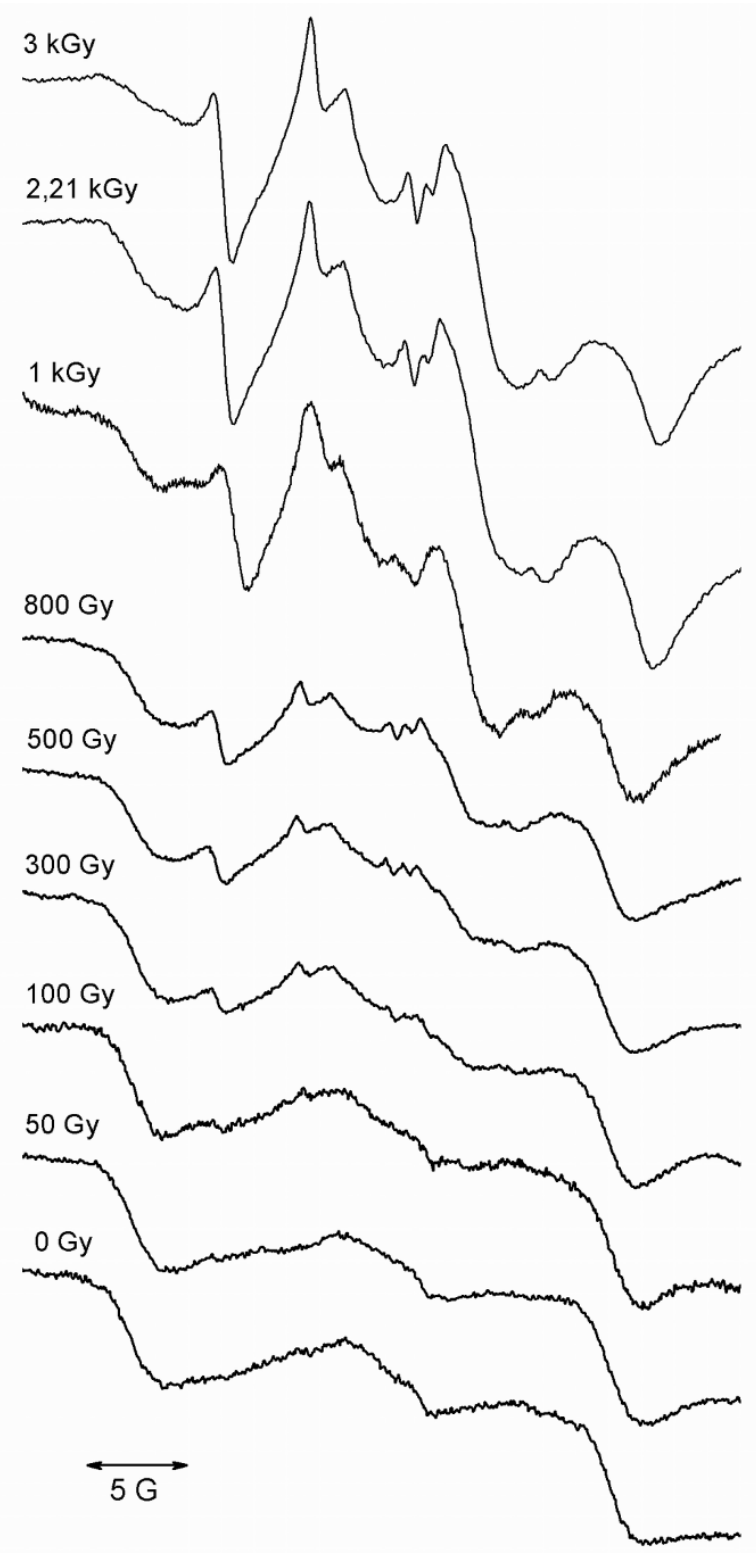

Fig. 7. EPR spectra of sample $61 \mathrm{H}$ unirradiated and irradiated with doses of 50, 100, 300, 500, 800, 1000, 2210 and 3000 Gy, sweep width $40 \mathrm{G}$.
Spectra recorded at $140 \mathrm{G}$ sweep width were subjected to the CREM procedure. It allowed to isolate previously indistinguishable peaks, and therefore determine more accurate $g$-factor values. Some of the enhanced spectra together with $g$-factor values obtained from them are shown in Fig. 8. Careful comparison of those spectra proves that they indeed consist of the same signals, but with various intensities and ratios. Only the main peaks of the enhanced spectra were analysed, and the results of the CREM procedure were carefully compared with the original spectra. The use of the CREM procedure is a valuable contribution to the investigation of the complex spectra of archaeological materials.

The EPR signals intensities of $\gamma$-induced paramagnetic centres attributed to carbonate species were plotted versus the dose of irradiation creating the dose response curve, as shown in Fig. 9. Peak-to-peak intensities were measured for signal at $g=2.0013$. The amplitudes were normalised using the manganese signals as a reference each measured amplitude was divided by the amplitude of $\mathrm{Mn}^{2+}$ line from the same spectrum. Exponential growth of the curve and saturation above $20 \mathrm{kGy}$ have been observed in the case of all samples. The fitted curve was described with the function (Dobosz and Krzyminiewski (2007a):

$$
y=y_{0}+A_{1} \exp \left(-\frac{x}{t_{1}}\right)
$$

The intensity of the signal decreased at $100 \mathrm{kGy}$, probably due to some recombination effects, therefore this point was excluded from the fit. Since the applied doses of irradiation were very high, the calculation of the paleodose would have a very high uncertainty, therefore it was not attempted. The level of saturation of the signals coming from each sample might contain more information on the dynamics of paramagnetic centres and the history of the material.

Another dose response curve was plotted for the sample $61 \mathrm{H} \gamma$-irradiated with doses 50-3000 Gy (Fig. 9, inset). Linear function was fitted to the points in this range of doses.

The amplitude ratios of the triplet peaks at $g=2.0264$, 2.0058 and 1.9855 remained constant after irradiation, which confirm they originate from the same paramagnetic centre.

\section{CONCLUSIONS}

The presence of $\gamma$-sensitive carbonate paramagnetic centres $\mathrm{CO}_{2}{ }^{-}$and $\mathrm{CO}_{3}{ }^{3-}$ in the samples of lime mortars and plasters from Hippos after irradiation have been observed by EPR spectroscopy, which could indicate that well-chosen samples might be suitable for dating. This method, however, would prefer the older materials. Moreover, the EPR investigation should be preceded by a careful examination in order to remove unbleached car- 


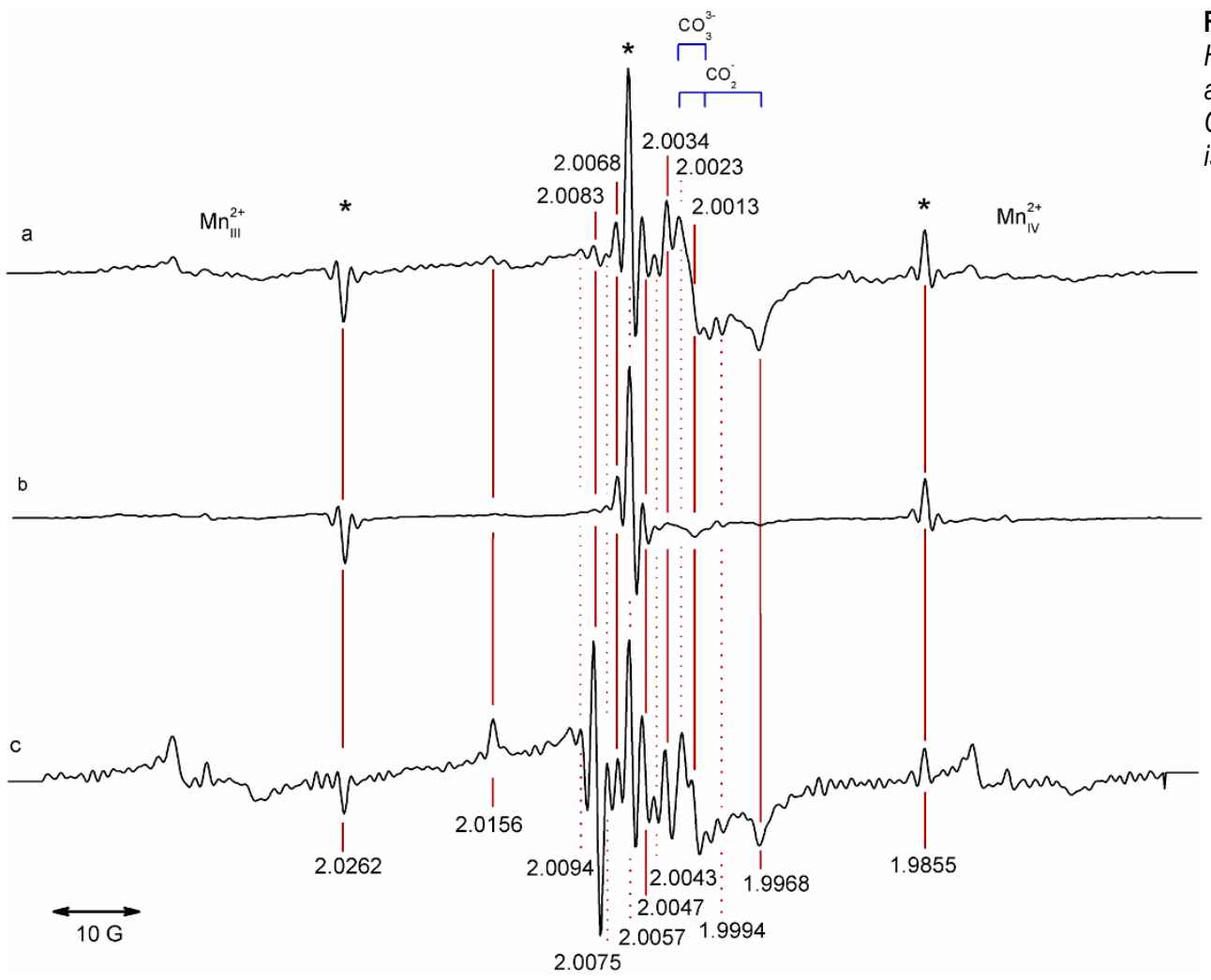

Fig. 8. EPR spectra of samples Hip10 (a), A1 (b) and 61H (c) irradiated with $20 \mathrm{kGy}$, after applying the CREM procedure. The triplet signal is marked with *.

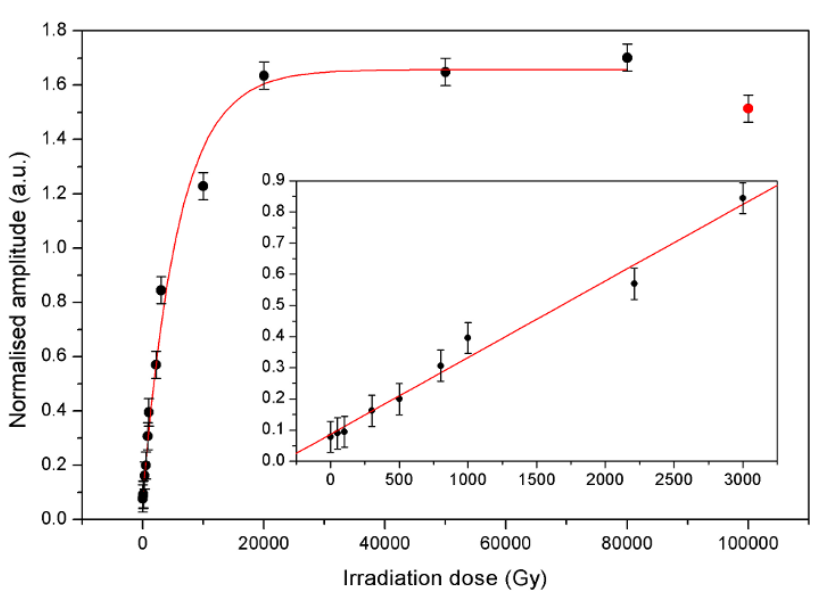

Fig. 9. Dose response curve for the signal at $g=2.0013$ in sample $61 \mathrm{H}$ (original spectrum). Each sample was measured 3-4 times, the points represent the mean values. Normalisation was conducted by dividing the amplitude of the peak by the amplitude of the fourth $\mathrm{Mn}^{2+}$ line. The data point at $100 \mathrm{kGy}$ was not used for curve fitting. Uncertainty of normalised amplitude was estimated as 0.05 . Equation of the fitted function was $y=y_{0}+A_{1} \exp \left(-x / t_{1}\right)$, with following values of the parameters: $\quad y_{0}=1.66 \pm 0.04, \quad A_{1}=-1.56 \pm 0.05, \quad t_{1}=5895.46 \pm 636.14$, $r^{2}=0.99103$. The inset shows a fragment of the curve for doses 0-3000 Gy, with linear fit $(y=a x+b)$ characterized by parameters: $a=0.08 \pm 0.01, b=2 \times 10^{-4} \pm 9 \times 10^{-6}$ and $r=0.99557$. bonate additives mixed with the mortar or plaster after heating. Such additives, as well as unburned limestone fragments which survived the heating and therefore might not be completely bleached, may significantly change the results of dating, giving much older dates.

The use of Computer Resolution Enhancement Method (CREM) allowed to isolate signals which otherwise would remain undistinguishable and determine more accurate spectroscopic parameters. This method has a huge potential in resolving the complex spectra often associated with archaeological samples.

More attempts of EPR dating of lime mortars and plasters are required, especially using samples from the building with well-established chronology, to compare the results obtained by different methods and verify the applicability of EPR to those materials. Mortars and plasters have a great value for archaeologists and searching for the new methods of dating them is highly desirable.

\section{ACKNOWLEDGMENT}

This work has been partially supported by the funds of the Polish Ministry of Science and Higher Education by grants No. IP2010027870 and No. N N307 059437, and Operational Program "Human Capital" - PO KL 4.1.1, "Proinnowacyjne kształcenie, kompetentna kadra, absolwenci przyszłości” („Pro-innovation training, competent staff, graduates of the future"). All samples were irradiated at the Institute of Applied Radiation Chemistry, 
Technical University of Łódź. Additionally, sample $61 \mathrm{H}$ was irradiated with doses of 50, 100, 300, 500, 800, 2210 and 3000 Gy at the Institute of Molecular Physics, Polish Academy of Sciences in Poznań. XRD analysis was performed at the Institute of Geology, Faculty of Geographical and Geological Sciences of Adam Mickiewicz University in Poznań by M. Kubiak. Radiocarbon dating was made by Prof. A. Pazdur in the Gliwice Radiocarbon Laboratory by GPC, and by Prof. T. Goslar in Poznań Radiocarbon Laboratory by AMS. The authors gratefully thank Prof. J. Młynarczyk (Institute of Archaeology, University of Warsaw), Dr M. Burdajewicz (National Museum in Warsaw), Prof. A. Segal and Dr M. Eisenberg (Zinman Institute of Archaeology, University of Haifa), the team leading the Hippos excavation at the time of sample collection, for cooperation in archaeological interpretation, and sample choice for analysis. Thanks are also due to Dr. M. Wencka for kind help and most valuable suggestions.

\section{REFERENCES}

Amiran DHK, Arieh E and Turcotte T, 1994. Earthquakes in Israel and adjacent areas: macroseismic observations since 100 BCE. Israel Exploration Journal 44: 260-305.

Barabas M, 1992. The nature of the paramagnetic centres at $g=2.0057$ and $g=2.0031$ in marine carbonates. Nuclear Tracks and Radiation Measurements 20(3): 453-464, DOI 10.1016/13590189(92)90031-P.

Barabas M, Bach A, Mudelsee M and Mangini A, 1992. General properties of the paramagnetic centre at $g=2.0006$ in carbonates. Quaternary Science Reviews 11(1-2): 165-171, DOI 10.1016/02773791(92)90059-H.

Callens F, Vanhaelewyn G, Matthys P and Boesman E, 1998. EPR of carbonate derived radicals: applications in dosimetry, dating and detection of irradiated food. Applied Magnetic Resonance 14(2-3): 235-254, DOI 10.1007/BF03161892.

Dobosz B and Krzyminiewski R, 2007a. Characteristic of paramagnetic centres in burnt clay and pottery by the EPR method. Radiation Measurements $\quad 42(2): \quad 213-219, \quad$ DOI 10.1016/j.radmeas.2006.11.003.

Dobosz B and Krzyminiewski R, 2007b. Linear transformation of EPR spectra as a method proposed for improving identification of paramagnetic species in ceramic. Applied Radiatiation and Isotopes 65(4): 392-396, DOI 10.1016/j.apradiso.2006.09.008.

Goedicke C, 2003. Dating historical mortars by blue OSL: results from known age samples. Radiation Measurements 37(4-5): 409-415, DOI 10.1016/S1350-4487(03)00010-6.

Goedicke C, 2011. Dating mortar by optically stimulated luminescence: a feasibility study. Geochronometria 38(1): 42-49, DOI 10.2478/s13386-011-0002-0.

Goslar T, Nawrocka D and Czernik J, 2009. Foraminiferous limestone in ${ }^{14} \mathrm{C}$ dating of mortar. Radiocarbon 51(3): 987-993.

Hale J, Heinemeier J, Lancaster L, Lindroos A and Ringbom A, 2003. Dating ancient mortar. American Scientist 91(2): 130-137, DOI 10.1511/2003.2.130.

Heinemeier J, Ringbom Å, Lindroos A and Sveinbjörnsdóttir Á, 2010. Successful AMS ${ }^{14} \mathrm{C}$ dating of non-hydraulic lime mortars from the medieval churches of the Åland Islands, Finland. Radiocarbon
52(1): 171-204.

Ikeya M, 1993. New Applications of Electron Spin Resonance: Dating, Dosimetry and Microscopy. World Scientifc, Singapore.

Ikeya M, 2004. EPR Dating, Dosimetry and Microscopy for Terrestrial and Planetary Materials. In: Gilbert BC, Davies MJ, Murphy DM, eds., Electron Paramagnetic Resonance. Specialist Periodical Reports (Royal Society of Chemistry) 19: 1-32.

Jonas M, 1997. Concepts and Methods of EPR Dating. Radiation Measurements 27(5-6): 943-973, DOI 10.1016/S13504487(97)00202-3.

Kabacińska Z, Krzyminiewski R, Dobosz B and Nawrocka D, 2012. EPR investigation of structure and dynamics of paramagnetic centres in lime mortars from Budinjak, Croatia. Radiation Measurements 47(9): 825-829, DOI 10.1016/j.radmeas.2012.03.017.

Krzyminiewski R, 1994. Computer Enhancement of Complex Spectroscopic Spectra Resolution. Molecular Physics Reports 6: 174-179.

Krzyminiewski R and Frąckowiak M, 2000. CREM in application to EPR dating technique. Geologos 5: 65-75.

Krzyminiewski R, Kowalczyk RM, Bielewicz-Mordalska A, Pająk Z and Czarnecki P, 1998. Computer enhancement of CW-EPR experimental spectra resolution as a new method in investigation of molecular dynamics in pyridiniumtetrafluoroborate. Journal of Molecular Structure 471(1-3): 243-249, DOI 10.1016/S00222860(98)00442-6.

Lindroos A, Heinemeier J, Ringbom Å, Braskén M and Sveinbjörnsdóttir Á, 2007. Mortar dating using AMS ${ }^{14} \mathrm{C}$ and sequential dissolution: examples from medieval, non-hydraulic lime mortars from the Åland Islands, SW Finland. Radiocarbon 49(1): 47-67.

Marco S, Hartal M, Hazan N, Lev L and Stein M, 2003. Archaeology, history, and geology of the A.D. 749 earthquake, Dead Sea transform. Geology 31(8): 665-668, DOI 10.1130/G19516.1.

Michniewicz J and Nawrocka D, 2005. Petrography of the plasters from Hippos. In: Segal A, Młynarczyk J, Burdajewicz M, Schuler M, Eisenberg M, Hippos-Sussita. Zinman Institute of Archaeology University of Haifa, Israel: 82-91. ISBN 965-90418-4-5.

Michalska Nawrocka D, Michczyńska DJ, Pazdur A and Czernik J, 2007. Radiocarbon chronology of the ancient settlement in the Golan Heights area, Israel. Radiocarbon 49: 625-637.

Młynarczyk J, 2001. Polsko-izraelskie wykopaliska w Hippos (Sussita) 2000-2001. Kosciol Polnocno-zachodni (NWC) (Polish-Israeli excavation in Hippos (Sussita) 2000-2001. North-West Church (NWC)). Światowit III (XLIV), fasc. A: 133-41 (in Polish).

Nawrocka D, Czernik J and Goslar T, 2009. ${ }^{14} \mathrm{C}$ Dating of carbonate mortars from Polish and Israeli sites. Radiocarbon 51: 857-866.

Nawrocka D, Michniewicz J, Pawlyta J and Pazdur A, 2005. Application of radiocarbon method for dating of lime mortars. Geochronometria 24: 109-115.

Polikreti K, Maniatis Y, Bassiakos Y, Kourou N and Karageorghis V, 2004. Provenance of archaeological limestone with EPR spectroscopy: the case of the Cypriote-type statuettes. Journal of Archaeological Science 31(7): 1015-1028, DOI 10.1016/j.jas.2003.12.013.

Segal A, Młynarczyk J, Burdajewicz M, Schuler M, Eisenberg M, 2004. Hippos (Sussita). Fifth Season of Excavations and Summary of All Five Seasons (2000-2004). Haifa: Zinman Institute of Archaeology, University of Haifa (in Hebrew and English)

Selețchi ED and Duliu OG, 2007. Comparative Study on EPR Spectra of Carbonates. Romanian Journal of Physics 52: 657-666.

Wencka M and Krzyminiewski R, 2004. Identification of paramagnetic centers and the dating of cave dripstones by electron paramagnetic resonance. Applied Magnetic Resonance 26(4): 561-578, DOI 10.1007/BF03166583.

Zacharias N, Mauz B and Michael CT, 2002. Luminescence quartz dating of lime mortars. A first research approach. Radiation Protection Dosimetry 101: 379-382. 